\title{
KAJIAN STABILITAS TERMAL DAN KARAKTER KOVALEN ZAT PENGAKTIF PADA ARANG AKTIF LIMBAH GERGAJIAN KAYU MERANTI (Shorea spp)
}

\author{
Harry S. J. Koleangan ${ }^{1)}$ \\ ${ }^{1)}$ Program Studi Kimia FMIPA Univesitas Sam Ratulangi, Manado 95115 \\ e-mail: koleanganharry@yahoo.com
}

\begin{abstract}
ABSTRAK
Telah dilakukan penelitian tentang peranan stabilitas termal dan karakter kovalen pada zat pengaktif pada arang aktif yang dibuat dari limbah gergajian kayu meranti dengan menggunakan agen pengaktif $\mathrm{CaCl}_{2}$ dan $\mathrm{H}_{3} \mathrm{PO}_{4}$. Hasil penelitian menunjukkan bahwa zat pengaktif yang memiliki karakter kovalen yang dominan menghasilkan arang aktif dengan daya serap tertinggi.

Kata kunci: agen pengaktivasi, karbon aktif, limbah gergajian kayu meranti

\section{THERMAL STABILITY AND COVALENT CHARACTER EVALUATION OF ACTIVATING AGENTS ON MERANTI (Shorea spp) TIMBER SAWMILL-WASTE ACTIVATED CARBON}

\begin{abstract}
A research considering the role of thermal stability and covalent character of activating agent on meranti timber sawmill-waste activated carbon using $\mathrm{H}_{3} \mathrm{PO}_{4}$ and $\mathrm{CaCl}_{2}$ as activating agents had been conducted. The result showed that the activating agent having higher covalent character yielded highest-adsorption activated carbon.
\end{abstract}

Keywords: , activating agent, timber sawmill-waste, activated carbon.

\section{PENDAHULUAN}

Indonesia memiliki potensi sumber daya alam yang besar, di antaranya potensi kehutanan yang dititikberatkan pada pemanfaatan kayu menjadi kayu lapis dan kayu gergajian. Kegiatan tersebut menghasilkan produk samping yaitu limbah berupa serbuk kayu yang umumnya hanya dibiarkan menumpuk, membusuk, dibuang ke aliran sungai, atau dibakar sehingga menyebabkan pencemaran lingkungan. Salah satu jenis kayu yang sering digunakan dalam industri kayu gergajian adalah kayu meranti (Shorea spp).

Salah satu jalan yang ditempuh untuk mengatasi masalah limbah ini adalah dengan memanfaatkannya menjadi serbuk arang aktif. Arang aktif adalah zat dengan daya jerap tinggi yang mempunyai aplikasi beragam dalam penjerapan zat-zat yang tidak diinginkan dari gas dan larutan. Semua bahan yang mengandung karbon dalam jumlah yang cukup tinggi dapat diubah menjadi arang aktif, tetapi hasil akhirnya akan bervariasi tergantung pada bahan baku, zat pengaktif dan kondisi proses aktivasi (Bansal et.al., 1988).

Proses aktivasi arang aktif ada dua macam, yaitu proses aktivasi fisika dan aktivasi kimia. Aktivasi fisika biasanya berlangsung pada suhu $800-1100^{\circ} \mathrm{C}$, sedangkan penggunaan zat kimia dalam aktivasi kimia menyebabkan proses aktivasi dapat dilakukan pada suhu yang lebih rendah. Pada aktivasi kimia, zat pengaktif akan masuk di antara sela-sela lapisan karbon heksagonal dan selanjutnya membuka permukaan yang tertutup (Bansal et.al., 1988). Dua zat pengaktif yang biasanya digunakan untuk tujuan ini adalah $\mathrm{H}_{3} \mathrm{PO}_{4}$ dan $\mathrm{CaCl}_{2}$. Sifat zat pengaktif yang berhubungan dengan mutu arang aktif adalah stabilitas termal dan karakter kovalen. Stabilitas termal berperan dalam mempertahankan kestabilan zat pengaktif dalam proses aktivasi yang dilakukan pada suhu tinggi sedangkan karakter kovalen berkaitan dengan interaksi 
kovalen antara arang dengan zat pengaktif yang berlangsung pada suhu tinggi untuk membuka pori arang. Dalam penelitian ini dikaji tentang peranan kedua sifat tersebut yang dikombinasi dengan variasi suhu dalam pembuatan arang aktif dari limbah kayu meranti.

\section{METODE PENELITIAN}

Bahan-bahan yang digunakan dalam penelitian ini adalah serbuk gergajian kayu meranti, $\mathrm{H}_{3} \mathrm{PO}_{4} 10 \%, \mathrm{CaCl}_{2} 10 \%$, larutan iod $0,1 \mathrm{~N}, \mathrm{Na}_{2} \mathrm{~S}_{2} \mathrm{O}_{3} 0,1 \mathrm{~N}$, larutan kanji $1 \%$, kertas saring, akuades.

Alat yang digunakan terbagi atas alat untuk pembuatan arang aktif dan alat untuk analisis mutu. Alat untuk pembuatan arang aktif: oven, tanur, neraca analitik, cawan porselen dengan penutup, mortar, saringan, wajan, burner, dan wadah plastik (ember). Alat untuk analisis mutu: cawan porselen dengan penutup, botol timbang, oven, tanur, desikator, kertas karbon, labu asah, peralatan titrasi dan peralatan gelas.

Preparasi sampel dilakukan sebagai berikut: serbuk gergaji kering $\pm 300 \mathrm{~g}$ dimasukkan ke dalam wadah plastik kemudian dicampur dengan $\mathrm{H}_{3} \mathrm{PO}_{4} 10 \%$ dan didiamkan selama 24 jam. Campuran ini kemudian dikeringkan dan dikarbonisasi sampai terbentuk arang. Karbonisasi dilakukan dengan cara mengarangkan serbuk kayu yang telah direndam dengan pengaktif diatas pemanas (burner). Setelah itu dimasukkan ke dalam tanur dengan suhu 500 ${ }^{\circ} \mathrm{C}$ selama 3 jam. Arang aktif yang dihasilkan lalu dicuci dengan akuades sampai $\mathrm{pH}$ air netral dan dikeringkan dalam oven pada suhu $110{ }^{\circ} \mathrm{C}$ selama \pm 3 jam. Perlakuan yang sama diulangi untuk aktivasi menggunakan suhu $600^{\circ} \mathrm{C}$ dan $700^{\circ} \mathrm{C}$ dengan menggunakan pengaktif $\mathrm{CaCl}_{2} 10 \%$, kemudian arang aktif siap untuk dianalisis. Analisis dilakukan untuk menentukan kadar zat mudah menguap, kadar abu, kadar karbon terikat dan daya jerap iod. Penentuan daya jerap iod dilakukan menggunakan prosedur dari American Society for Testing and Material (1999).

Penelitian ini dilaksanakan dengan menggunakan rancangan percobaan faktorial yang disusun dalam Rancangan Acak Lengkap (RAL), yang terdiri dari dua faktor yaitu jenis pengaktif dan suhu aktivasi. Masing-masing kombinasi perlakuan diulang tiga kali.

\section{HASIL DAN PEMBAHASAN}

Hasil analisis daya jerap purata arang aktif dari limbah kayu meranti disajikan dalam Gambar 1.

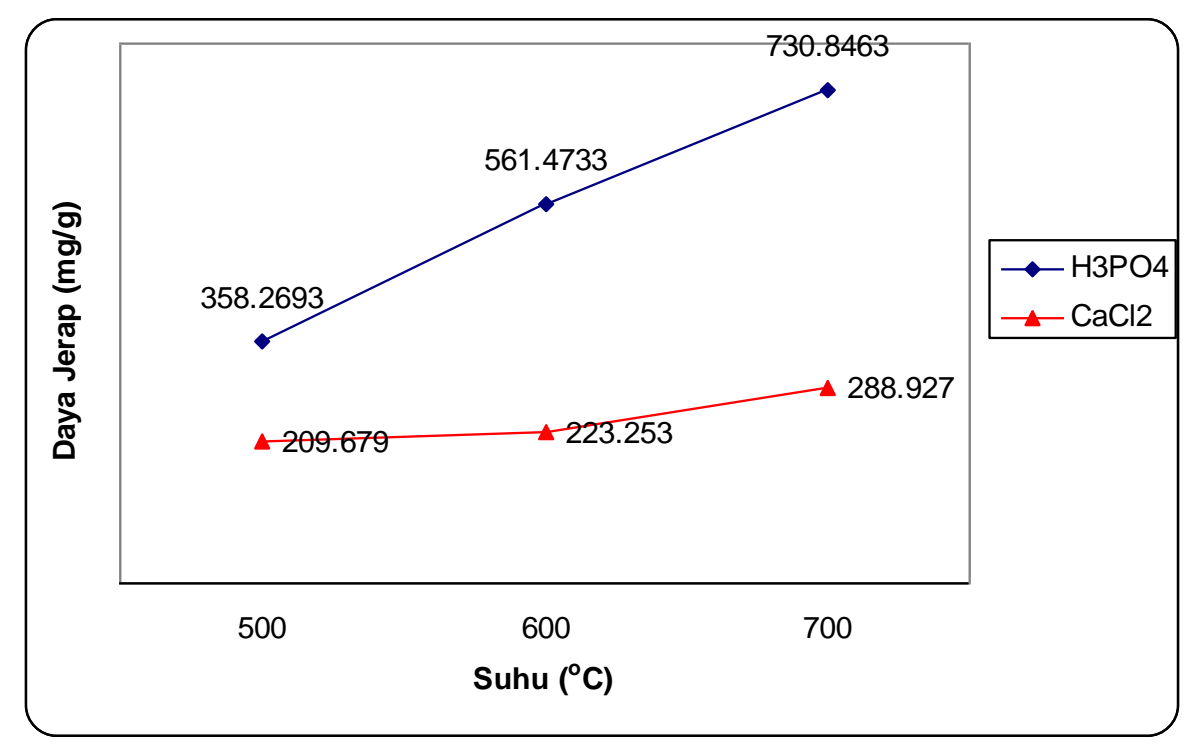

Gambar 1. Daya Serap Purata Arang Aktif dari Limbah Kayu Meranti 
Dari Gambar 1 terlihat adanya perbedaan daya jerap purata antara arang aktif yang dihasilkan menggunakan zat pengaktif $\mathrm{H}_{3} \mathrm{PO}_{4}$ dengan arang aktif yang diaktivasi dengan $\mathrm{CaCl}_{2}$. Perbedaan daya jerap ini didukung oleh analisis statistik (Lampiran) yang menyimpulkan bahwa daya jerap purata arang aktif yang diaktivasi menggunakan $\mathrm{H}_{3} \mathrm{PO}_{4}$ berbeda signifikan (dengan tingkat keyakinan 95\%) dibandingkan dengan daya jerap purata arang aktif yang diaktivasi menggunakan $\mathrm{CaCl}_{2}$.

Dari hasil ini juga nampak bahwa daya jerap purata arang aktif yang dihasilkan menggunakan zat pengaktif $\mathrm{H}_{3} \mathrm{PO}_{4}$ adalah lebih tinggi dibandingkan dengan yang dihasilkan oleh zat pengaktif $\mathrm{CaCl}_{2}$. Hal ini menunjukkan bahwa $\mathrm{H}_{3} \mathrm{PO}_{4}$ berperan lebih sangkil dalam membuka pori pada arang sehingga arang aktif yang dihasilkannya memiliki daya jerap yang lebih baik. Kesangkilan kedua pengaktif ini dalam proses aktivasi arang dapat dipengaruhi oleh dua faktor, yaitu stabilitas termal dan karakter kovalen dari zat tersebut.

Stabilitas termal dari kedua zat pengaktif tercermin dari entalpi $\left(\Delta H^{\theta}\right)$ dekomposisi masing-masing zat, di mana stabilitas termal akan semakin baik dengan semakin tingginya entalpi dekomposisi (Shriver et.al., 1990). Dari penelusuran pustaka diketahui $\Delta H^{\theta} \quad \mathrm{CaCl}_{2}=795,8$ $\mathrm{kJ} / \mathrm{mol}$ dan $\Delta H^{\theta} \quad \mathrm{H}_{3} \mathrm{PO}_{4}=964,4 \mathrm{~kJ} / \mathrm{mol}$ (Atkins, 1990). Dari data ini nampak bahwa $\mathrm{H}_{3} \mathrm{PO}_{4}$ memiliki stabilitas termal lebih baik dari $\mathrm{CaCl}_{2}$, sehingga secara teoritis pada proses pengarangan akan lebih banyak $\mathrm{H}_{3} \mathrm{PO}_{4}$ yang tersedia dibandingkan $\mathrm{CaCl}_{2}$. Gambar 1 menunjukkan bahwa sepertinya faktor stabilitas termal membuat $\mathrm{H}_{3} \mathrm{PO}_{4}$ menjadi lebih sangkil dibandingkan $\mathrm{CaCl}_{2}$ karena lebih tingginya daya jerap arang yang diaktivasi menggunakan $\mathrm{H}_{3} \mathrm{PO}_{4}$ pada semua suhu. Namun, apabila ditelaah lebih dalam dengan membandingkan daya jerap arang aktif pada ketiga suhu, terlihat bahwa dengan meningkatnya suhu tidak membuat daya jerap menjadi lebih rendah. Dengan kata lain, pada kisaran suhu $500^{\circ} \mathrm{C}$ sampai $700^{\circ} \mathrm{C}$ belum membawa pengaruh yang berarti pada kestabilan termal kedua zat tersebut. Jadi ada faktor lain yang lebih menentukan dibandingkan faktor stabilitas termal. Faktor itu adalah perbedaan karakter kovalen dari zat pengaktif.

Unsur-unsur yang menyusun $\mathrm{H}_{3} \mathrm{PO}_{4}$ berikatan secara kovalen polar sedangkan pada $\mathrm{CaCl}_{2}$ unsur-unsur penyusunnya berikatan secara ionik. Dengan demikian senyawa $\mathrm{H}_{3} \mathrm{PO}_{4}$ lebih didominasi oleh karakter kovalen, sedangkan $\mathrm{CaCl}_{2}$ didominasi oleh karakter ionik. Perbedaan karakter kovalen antara $\mathrm{H}_{3} \mathrm{PO}_{4}$ dengan $\mathrm{CaCl}_{2}$ memiliki dampak terhadap interaksinya dengan arang. Arang, yang tersusun dari atom- atom $\mathrm{C}$ yang secara kovalen membentuk struktur heksagonal datar dengan satu atom C pada tiap sudut, akan berinteraksi lebih baik dengan zat yang memiliki karakter kovalen dibandingkan dengan zat berkarakter ionik. Jadi, $\mathrm{H}_{3} \mathrm{PO}_{4}$ memiliki kemampuan berinteraksi lebih baik dengan arang, dalam hal ini lebih sangkil dalam membuka pori pada arang, dibandingkan dengan $\mathrm{CaCl}_{2}$. Hasilnya nampak pada lebih tingginya daya jerap pada arang yang dihasilkan dengan menggunakan pengaktif $\mathrm{H}_{3} \mathrm{PO}_{4}$ (Gambar 1).

Uji statistik (Lampiran) juga menunjukkan bahwa terdapat perbedaan signifikan (dengan tingkat keyakinan 95\%) pada daya jerap purata antara arang aktif yang diaktivasi pada suhu $500^{\circ} \mathrm{C}, 600^{\circ} \mathrm{C}$, dan $700^{\circ} \mathrm{C}$, baik yang menggunakan $\mathrm{H}_{3} \mathrm{PO}_{4}$ maupun $\mathrm{CaCl}_{2}$. Uji Beda Nyata Jujur (BNJ) pada lampiran yang sama menunjukkan bahwa daya jerap purata pada arang yang dihasilkan oleh ketiga suhu tersebut ternyata berbeda secara signifikan dengan tingkat keyakinan 95\%, baik pada arang yang menggunakan pengaktif $\mathrm{H}_{3} \mathrm{PO}_{4}$ maupun $\mathrm{CaCl}_{2}$ di mana daya jerap tertinggi diperoleh dari arang yang diaktivasi pada suhu $700^{\circ} \mathrm{C}$ dengan menggunakan pengaktif $\mathrm{H}_{3} \mathrm{PO}_{4}$.

Dari Gambar 1 juga nampak bahwa daya jerap purata tertinggi diperoleh pada proses aktivasi menggunakan suhu $700^{\circ} \mathrm{C}$ kemudian, $\quad 600^{\circ} \mathrm{C}$ dan $500^{\circ} \mathrm{C}$, baik menggunakan pengaktif $\mathrm{H}_{3} \mathrm{PO}_{4}$ maupun $\mathrm{CaCl}_{2}$. Hal ini menunjukkan penggunaan suhu $700^{\circ} \mathrm{C}$ berperan lebih sangkil dalam membuka pori pada arang sehingga memberikan hasil arang aktif yang memiliki daya jerap yang lebih baik. Kemampuan membuka pori ini berhubungan dengan suhu yang digunakan dalam proses aktivasi. Suhu tinggi berkaitan langsung dengan jumlah energi yang terlibat dalam proses aktivasi 
karena semakin tinggi suhu semakin besar energi yang terlibat dalam proses aktivasi. Semakin banyak energi yang digunakan dalam aktivasi, semakin banyak pori yang terbuka sehingga semakin baik daya jerap dari karbon aktif yang dihasilkan.

Secara keseluruhan, daya jerap terbaik diperoleh dari arang aktif diaktivasi menggunakan pengaktif $\mathrm{H}_{3} \mathrm{PO}_{4}$ dan suhu aktivasi $700^{\circ} \mathrm{C}$, yaitu dengan hasil purata $730,8463 \mathrm{mg} \mathrm{I}_{2}$ per gram arang aktif.

\section{KESIMPULAN}

Berdasarkan hasil penelitian maka dapat disimpulkan:

1. Perbedaan stabilitas termal antara $\mathrm{H}_{3} \mathrm{PO}_{4}$ dengan $\mathrm{CaCl}_{2}$ belum membawa pengaruh yang berarti daya jerap arang aktif dari limbah kayu gergajian yang diaktivasi pada suhu $500^{\circ} \mathrm{C}, 600^{\circ} \mathrm{C}$, dan $700^{\circ} \mathrm{C}$.

2. Karakter kovalen yang lebih dominan pada $\mathrm{H}_{3} \mathrm{PO}_{4}$ membuat agen pengaktif ini lebih sangkil dalam aktivasi arang dari limbah gergajian kayu meranti.

3. Arang aktif dengan daya jerap terbaik diperoleh menggunakan pengaktif $\mathrm{H}_{3} \mathrm{PO}_{4}$ dan suhu aktivasi $600^{\circ} \mathrm{C}$, yaitu dengan hasil purata $861,0579 \mathrm{mg} \mathrm{I_{2 }}$ per gram arang aktif.

\section{DAFTAR PUSTAKA}

American Society for Testing and Material. 1999. Standard Test Method for Determination of Iodine Number of Activated Carbon. ASTM. Philadelphia.

Atkins, P. W. 1990. Physical Chemistry. W. H. Freeman and Company. New York.

Bansal, C. R. , J. B. Donnet, F. Stoeckli . 1988. Active Carbon. Marcel Dekker Inc. New York .

Pari, G. 2002. Teknologi alternatif pemanfaatan limbah industri pengolahan kayu. http : //rudyet.tripod.com/sem 2.012 gustanpari.htm.

Shriver, E. F., P. W. Atkins, C. H. Langford. 1990. Inorganic Chemistry. Oxford University Press. Oxford.

Lampiran. Analisis Sidik Ragam Daya Jerap Purata Arang Aktif dari Limbah Kayu Meranti

ANOVA

\begin{tabular}{|l|r|r|c|c|c|c|}
\hline Sumber Ragam & \multicolumn{1}{|c|}{$J K$} & \multicolumn{1}{|c|}{$d b$} & $K T$ & $F$ & $P$-value & F crit \\
\hline Jenis Pengaktif & 431268.8 & 1 & 431268.8 & 6169.436 & $1.21 \mathrm{E}-17$ & 4.747225 \\
Suhu & 153192.8 & 2 & 76596.41 & 1095.736 & $2.61 \mathrm{E}-14$ & 3.885294 \\
Interaksi & 66377.46 & 2 & 33188.73 & 474.7753 & $3.78 \mathrm{E}-12$ & 3.885294 \\
Galat & 838.849 & 12 & 69.90408 & & & \\
\hline Total & 651677.9 & 17 & & & & \\
\hline
\end{tabular}




\section{Uji Beda Nyata Jujur (BNJ)}

\section{Pengujian Efek Sederhana}

1. Pengaruh suhu pada masing- masing jenis zat pengaktif

$$
B N J_{0,05}=q\left(p_{1}, n\right) \times \sqrt{K T_{(\text {galat })} / r}=18,198349
$$

Di mana : $q\left(p_{1}, n\right)=$ nilai dari tabel $q$ pada kolom ke- $p_{1}$ dan baris ke- $n$

$p_{1}=$ banyak perlakuan suhu $(=3)$

$n=$ derajat bebas galat $(=12)$

$r=$ banyaknya ulangan $(=3)$

2. Pengaruh jenis pengaktif pada masing-masing suhu

$$
B N J_{0,05}=q\left(p_{2}, n\right) \times \sqrt{K T_{(\text {galat })} / r}=14,867617
$$

Di mana $: q\left(p_{2}, n\right)=$ nilai dari tabel $q$ pada kolom ke- $p_{2}$ dan baris ke- $n$

$$
\begin{aligned}
& p_{2}=\text { banyak jenis kayu }(=2) \\
& n=\text { derajat bebas galat }(=12)
\end{aligned}
$$

\begin{tabular}{|c|c|c|c|c|}
\hline \multirow{2}{*}{$\begin{array}{c}\text { Jenis } \\
\text { Pengaktif }\end{array}$} & \multicolumn{3}{|c|}{ Suhu $\left({ }^{\circ} \mathbf{C}\right)$} & \multirow{2}{*}{ Keterangan } \\
\hline & 500 & 600 & 700 & \\
\hline $\mathrm{H}_{3} \mathrm{PO}_{4}$ & $\begin{array}{l}358.2693 a \\
\text { A }\end{array}$ & $\begin{array}{c}561.4733 b \\
\text { A }\end{array}$ & $\begin{array}{c}730.8463 \mathrm{c} \\
\mathrm{A}\end{array}$ & $\begin{array}{l}\text { Huruf kecil ke samping untuk pengujian } \\
\text { suhu. }\end{array}$ \\
\hline $\mathrm{CaCl}_{2}$ & $\begin{array}{l}209.6793 a \\
\text { B }\end{array}$ & $\begin{array}{c}223.2533 a \\
\text { B }\end{array}$ & $\begin{array}{l}288.9273 b \\
\text { B }\end{array}$ & $\begin{array}{l}\text { Huruf besar ke bawah untuk pengujian } \\
\text { jenis pengaktif. }\end{array}$ \\
\hline
\end{tabular}

$r=$ banyaknya ulangan $(=3)$

Tabel Pengujian Efek Sederhana 